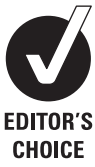

For numbered affiliations see end of article

\section{Correspondence to} Dr Margo Mountjoy, Health and Performance Centre, John T. Powell Building, 2nd floor, University of Guelph Guelph, ON, N1G 2W1, Canada;

mmsportdoc@aol.com

Accepted 3 June 2011

\title{
International Olympic Committee consensus statement on the health and fitness of young people through physical activity and sport
}

\author{
Margo Mountjoy, ${ }^{1} 2$ Lars Bo Andersen, ${ }^{3}$ Neil Armstrong, ${ }^{4}$ Stuart Biddle, ${ }^{5}$ \\ Colin Boreham, ${ }^{6}$ Hans-Peter Brandl Bedenbeck, ${ }^{7}$ Ulf Ekelund, ${ }^{8,9}$ Lars Engebretsen, ${ }^{1,10}$ \\ Ken Hardman, ${ }^{11}$ Andrew Hills, ${ }^{12}$ Sonja Kahlmeier, ${ }^{13}$ Susi Kriemler, ${ }^{14}$ Estelle Lambert, ${ }^{15}$ \\ Arne Ljungqvist, ${ }^{1}$ Victor Matsudo, ${ }^{16}$ Heather McKay, ${ }_{1}^{17}$ Lyle Micheli, ${ }^{18}$ Russell Pate, ${ }^{19}$ \\ Chris Riddoch, ${ }^{20}$ Patrick Schamasch, ${ }^{1}$ Carl Johan Sundberg, ${ }^{21}$ Grant Tomkinson, ${ }^{22}$ \\ Esther van Sluijs, ${ }^{23}$ Willem van Mechelen ${ }^{24}$
}

\section{INTRODUCTION}

The International Olympic Committee (IOC) recognises the health and fitness benefits of physical activity (PA) and sport as stated in recommendation \#51 from the Olympic Movement in Society Congress held in Copenhagen, 2009:

\begin{abstract}
Everyone involved in the Olympic Movement must become more aware of the fundamental importance of Physical Activity and sport for a healthy lifestyle, not least in the growing battle against obesity, and must reach out to parents and schools as part of a strategy to counter the rising inactivity of young people. ${ }^{1}$
\end{abstract}

The IOC assembled an expert group (January 2011) to discuss the role of PA and sport on the health and fitness of young people and to critically evaluate the scientific evidence as a basis for decision making. Specifically, the purpose of this consensus paper is to identify potential solutions through collaboration between sport and existing programmes and to review the research gaps in this field. The ultimate aim of the paper is to provide recommendations for young people's sport and PA stakeholders.

After an introduction to the scope of the problem, issues addressed include how best to define the current state of fitness and PA of young people; health consequences due to the lack of PA and/ or sport; correlates and determinants of PA and sedentary behaviour; options for change: studies on effectiveness of intervention; and context for action: potential solutions. Finally, a summary and recommendations are given.

\section{Scope of the problem}

Insufficient PA has been classified by the WHO as the fourth leading risk factor for global mortality from non-communicable diseases (NCDs) after hypertension, tobacco use and high blood glucose. Insufficient PA is responsible for $3.2 \mathrm{mil}$ lion or $5.5 \%$ of all deaths. ${ }^{23}$ In addition, scientific evidence shows that insufficient levels of PA are adversely affecting the health and the health trajectory of young people. ${ }^{45}$ Another alarming trend is that young people's PA levels are declining as they move through childhood into adolescence 6 and these patterns of sedentary behaviour may even track into adulthood. ${ }^{7}$ The detrimental health effects of inadequate levels of PA in young people are well established ${ }^{9-12}$ and evidence on the negative health effects of sedentary behaviour is growing. ${ }^{13} \mathrm{PA}$, including through involvement in sport, is instrumental in the prevention of NCDs that carry a high burden of individual health costs as well as economic consequences to society.

\section{Defining the current state of fitness and PA of young people}

\section{Are today's young people active?}

The assessment and interpretation of young people's PA is one of the most difficult tasks in epidemiology. PA and sport participation during youth have historically been assessed by self-report but the criterion validity of self-reported instruments is low to moderate with correlation coefficients usually between 0.3 and $0.4 .^{14-16}$ Furthermore, self-report instruments tend to overestimate the intensity and duration of PA and sport participation. ${ }^{15}$ However, self-report methods can provide information about types of PA, the setting and contexts in which PA takes place and the amount of PA devoted to specific domains.

Recent, large-scale observational studies have used objective monitoring of PA by accelerometry. This innovation has substantially increased our knowledge of PA and how PA is associated with health outcomes in youth. ${ }^{17}$ However, interpreting PA data from accelerometry during childhood and adolescence is challenging. Methodological issues include the definition of PA intensity thresholds, and there is no consensus on the most appropriate PA intensity thresholds to use when measuring young people's PA by accelerometry. ${ }^{14} 18$

Self-reported PA suggests that $30-40 \%$ of young people satisfy current health-related PA recommendations. ${ }^{1920}$ Accelerometry data are more variable but most studies using PA intensity thresholds above 3000 counts per minute (broadly equivalent to brisk walking) indicate that they are achieved by less than $25 \%$ of young people. ${ }^{4621}$ Sport participation contributes to higher levels of PA in youth. ${ }^{22}$ 
It is unlikely that any self-report method is sufficiently accurate for examining cross-cultural differences and temporal trends in young people's sport participation and PA. However, recent self-report studies suggest that PA levels have not declined during recent decades. ${ }^{20}$ This observation is supported by the few studies that have assessed PA objectively. ${ }^{23} 24$ However, data on temporal trends should be interpreted cautiously as PA levels may have declined in domains not assessed by these instruments. ${ }^{25}$

\section{Are today's young people fit?}

Peak oxygen uptake $\left(\mathrm{VO}_{2}\right)$ is the best single measure of young people's aerobic fitness. During growth and maturation, peak $\mathrm{VO}_{2}$ benefits from increases in muscle mass, stroke volume and, particularly in boys, blood haemoglobin concentration. Young people's peak $\mathrm{VO}_{2}$ increases with age and boys' values are higher than those of girls throughout childhood and adolescence, regardless of whether peak $\mathrm{VO}_{2}$ is expressed in absolute $(1 / \mathrm{min})$ or body mass-related $(\mathrm{ml} / \mathrm{kg} / \mathrm{min})$ terms. ${ }^{26} 27$

A high peak $\dot{\mathrm{VO}}_{2}$ is a prerequisite of elite performance in many sports but, in several sports and in everyday life, intermittent exercise and the ability to engage in rapid changes of exercise intensity is at least as important as achieving maximal aerobic performance. Under these conditions, it is the transient kinetics of $\mathrm{VO}_{2}$ which best describes the relevant component of aerobic fitness. In youth, peak $\mathrm{VO}_{2}$ is not related to the primary component, time constant $(\tau)$, during the transition from rest to exercise. The $\dot{\mathrm{VO}}_{2}$ kinetics response to exercise is age dependent and boys have a shorter $\tau$ than girls during the transition from rest to heavy intensity exercise. ${ }^{28} 29$

Young athletes have higher peak $\dot{\mathrm{VO}}_{2}$ and faster $\tau$ than their untrained peers. Both trained and untrained youth benefit from exercise training. ${ }^{30}$ Young people, however, rarely experience habitual PA of the duration and intensity sufficient to enhance peak $\dot{V O}_{2}$ and there is no meaningful relationship between habitual PA and this component of aerobic fitness. ${ }^{31}$ The relationship between habitual PA and $\mathrm{VO}_{2}$ kinetics remains to be investigated.

Data on $\dot{\mathrm{VO}}_{2}$ kinetics in youth are sparse but the peak $\dot{\mathrm{VO}}{ }_{2}$ of young people is well documented. There are no widely recognised recommendations for health-related levels of aerobic fitness in youth and no compelling evidence to suggest that young people have low levels of peak $\mathrm{VO}_{2}(1 / \mathrm{min})$ or that they are less aerobically fit than young people of the previous generations. ${ }^{32}$ There has been a very small decline of about $0.1 \%$ per decade in mass-related peak $\mathrm{VO}_{2}(\mathrm{ml} / \mathrm{kg} / \mathrm{min})$ between 1962 and 1994. In contrast, there has been a substantial deterioration of about $4.0 \%$ per decade in maximal aerobic performance, since 1975. It is not clear whether these temporal changes have been uniform or skewed over time, although changes were typically more marked in young people who are less fit. ${ }^{33}$ Declines in maximal aerobic performance are likely the result of a network of social, behavioural, physical, psychological and physiological factors. Irrespective of the underlying mechanisms, it is the diminished aerobic performance that has the greatest implications for youth health and wellbeing, and successful sport participation. ${ }^{34}$

\section{Health consequences of lack of physical fitness, PA and/or sport}

\section{Cardiovascular and metabolic health}

Research focused on the cardiovascular consequences of inactivity in young people has primarily used two methodologies: interventional studies, in which PA is increased in a given population, and observational studies, in which cardiovascular markers have been compared with levels of PA in a subject population. 5113536

Exercise training interventions in normotensive youth have been found to have little effect on blood pressure, but prolonged programmes in hypertensive youth have had a salutary effect. ${ }^{37-46}$ In addition, observational studies have reported a positive association between aerobic fitness levels and blood pressure. ${ }^{45} 46$ It can be concluded that a PA intervention of at least $30 \mathrm{~min}$, three times per week with intensity sufficient to increase aerobic fitness can effectively reduce blood pressure in youth with essential hypertension.

Studies of the effect of activity levels and exercise interventions on blood lipid levels in young people suggest that a minimum of 40 min of activity per day, 5 days per week and with a duration of at least 4 months is required to achieve improvement in lipid and lipoprotein levels, demonstrating primarily increased HDL-C and decreased triglyceride levels. ${ }^{35} 4748$ Interventions have included aerobic training, resistance training and circuit training. 54349

Metabolic syndrome was first described as a constellation of risk factors for cardiovascular disease in adults, including abdominal obesity, type II diabetes, hypertension and increased levels of inflammatory markers. However, it is now estimated that metabolic syndrome characteristics exist in $3-14 \%$ of all youth and is increasing as obesity in youth increases. ${ }^{50-53}$ Observational studies have found a close association between low PA levels and metabolic syndrome in youth. ${ }^{5} 5455$ Interventional studies have shown improvements of elements of metabolic syndrome with increased PA in both obese and non-obese youth. The amount of PA necessary to prevent or treat metabolic syndrome has not yet been defined. $434956-59$

Few studies have examined the relationship of muscular fitness to cardiovascular risk factors in young people, but the studies available demonstrate a negative association between muscle fitness and clustered metabolic risk. ${ }^{60-62}$

In summary, the current scientific literature suggests that low levels of PA in young people are associated with higher levels of obesity, hypertension and cardiovascular risk factors, including increased instances of metabolic syndrome.

\section{Bone health}

Bone is a dynamic tissue that varies between individuals as a function of age, sex, genetics and lifestyle. Bone geometry, mass and structure contribute to bone strength, which largely determines bone's susceptibility to fracture. Fractures affect approximately $30-50 \%$ of both young ${ }^{63} 64$ and old populations. ${ }^{65} \mathrm{PA}$ is key to enhanced bone mass, structure and strength and these beneficial effects were summarised in recent reviews. ${ }^{66-71}$

Animal studies clearly demonstrate that dynamic loading of short duration with multiple rest pauses is most effective for bone formation. ${ }^{72}$ Young athletes engaged in weight-bearing activities across a range of sports have augmented bone mass compared with non-athletic peers. ${ }^{73-76}$ Racquet sport athletes who began training in early puberty have significantly stronger bones on their playing $\operatorname{arm}^{77}$ compared with their non-playing arm and benefits persist over time. ${ }^{78}$ Thus, early puberty provides a 'window of opportunity' when bone is most responsive to PA and sport than at any other time during the life course.

A number of effective interventions have typically involved vigorous jumping and other activities across the school day, 
at least three times per week for between 6 and 24 months. A recent systematic review of randomised and non-randomised controlled trials of weight bearing exercise concluded that bone mass and density gains at the femoral neck and lumbar spine ranged from $1 \%$ to $6 \%$ before puberty and from $0.3 \%$ to $2 \%$ postpuberty. ${ }^{79}$ However, attention has increasingly shifted from measures of bone mass to potentially more important measures of bone geometry, structure and strength. Recent studies, ${ }^{80}$ reviews ${ }^{81}$ and meta-analyses ${ }^{70}$ assessed exercise effects on bone strength during growth and reported small but significant effects on the lower extremities in young people. The bone response to exercise depends upon the sex and maturity level of the young person, the anatomical site measured and the length and intensity of the intervention. Epidemiological studies used objective measures of $\mathrm{PA}^{82-84}$ and corroborated the benefit of weight-bearing PA for young people's bone health.

Taken together, a wide range of extra-curricular sports, other activities and targeted school-based programmes provide a weight-bearing stimulus that promotes young people's bone health. ${ }^{85}$ Although bone strength benefits persist into old age in animal studies, ${ }^{86}$ there is little direct evidence that the enhanced 'bone bank' similarly persists into old age in humans as these long-term studies are challenging to conduct. However, longer term follow-up studies in young people $e^{87}$ and retrospective studies of athletes ${ }^{88} 89$ support this notion.

\section{Obesity}

Globally, obesity is affecting an increasing proportion of young people. ${ }^{9091} \mathrm{PA}$ during the growing years is important for the physical growth and development of all young people ${ }^{92}$ and is associated with numerous health benefits, including lowering the levels of overweight and obesity and reducing the risk of obesity in adulthood. Higher levels of PA and exercise, including sports participation, may translate to greater benefits. In recent decades, active behaviours have been displaced by more sedentary pursuits, which have contributed to reductions in PA energy expenditure. Typically, obese young people are less active than their normal-weight peers. ${ }^{93}$ While many reports suggest that young people's participation in organised sport and PA is high or has increased in some populations, incidental PA and exercise, including active transport such as walking to and from school, has declined in recent decades. Numerous environmental and lifestyle changes have contributed to these reductions. ${ }^{94}$

From a public health perspective, the promotion of a healthy diet and of PA and exercise are equally important factors for the maintenance of a healthy weight and body composition and reduction of chronic disease risk. ${ }^{95} 96$

\section{Mental health}

Review-level evidence with young people has shown small-tomoderate beneficial effects for reduced depression and anxiety from PA, but the evidence base is weak. Intervention designs are low in quality, and many reviews include cross-sectional studies. However, the beneficial effects of PA on reducing depression and anxiety are comparable with psychosocial interventions. ${ }^{97}$ PA can lead to small improvements in global self-esteem, at least in the short term. ${ }^{98}$ However, there is a paucity of good-quality research and future work may need to focus on physical aspects of the self. Reviews of PA and cognitive functioning have shown evidence that routine PA can be associated with improved cognitive performance, classroom behaviour and academic achievement in young people, but these associations are usually small. Additional allocation of time to PA in schools at the expense of academic class time does not affect academic performance. ${ }^{99}$

Results from recent primary studies have shown consistent small negative associations between mental health and sedentary behaviour, primarily screen viewing, with half controlling for PA. One longitudinal study did show that television viewing was associated with increased odds of depression after a 7-year follow-up. ${ }^{100}$

Little research has specifically addressed sport participation and mental health separate from participation in PA more broadly. Moreover, it is difficult to ascertain effects for low fit or low active youth.

\section{Injury risk}

Another health problem to be considered in young people lacking adequate PA is lower fitness levels which, over time, can increase the risk of injury in sport. ${ }^{101}$

Inadequate physical fitness is an intrusive risk factor for sports injury in young people and has been cited for some years. ${ }^{102}$ More recently, Emery has identified it as one of the potentially modifiable risk factors. ${ }^{103} 104$

Training measures to improve fitness and prevent injury in the young athlete include strength and flexibility training, plyometrics, balance and coordination training and techniques of cutting, landing and agility. ${ }^{105-116}$

One class of injury that has received increased attention in recent years is non-contact anterior cruciate ligament injuries in adolescent female athletes. ${ }^{106}$ Interventional studies have emphasised plyometrics, flexibility and aerobic training, balance and proprioception training, with most studies finding an association between training interaction and decreased injuries. ${ }^{106} 108-118$

Prevention of ankle sprains in young athletes through training interventions has also received much attention. ${ }^{119-124}$

A recent series of studies from The Netherlands of young people exposed to a fitness education and classroom training programme demonstrated a decrease in sports injuries, particularly in the previously less active participants. ${ }^{125} 126$

An ideal system for preventing sports injuries due to lower levels of fitness would entail a preparticipation evaluation of each participant followed by a training prescription to address individual deficits in fitness levels.

\section{Correlates and determinants of PA and sedentariness}

In order to better understand the 'mechanism' behind PA and sedentariness of young people, it is necessary to have an insight into the correlates and determinants of these behaviours. Roughly speaking, the correlates and determinants of these behaviours can be categorised into biological, psychosocial, behavioural, social and environmental factors. In reference to these five categories, the main findings of two reviews that were carried out for the purpose of this consensus statement are summarised below.

\section{Determinants of PA}

Uijtdewilligen et al ${ }^{127}$ conducted a systematic review on the determinants of PA building on a review on the same topic published in 2007. In contrast to the 2007 review, the current review only took into account prospective studies. The review concerned studies that were published between January 2004 and November 2010. Twenty-seven papers were identified. A best-evidence synthesis was applied to summarise the results. The following conclusions were drawn from the data regarding 
6-12 year olds: insufficient evidence was found for a longitudinal association between parent education and PA; moderate evidence was found for a longitudinal association between intention and the child's PA. Determinants of adolescents' PA were age (being older), ethnicity (not being African American) and planning. From the review of Uijtenwilligen, one must conclude that we have little 'true' high-quality information about the determinants of PA in youth.

\section{Correlates and determinants of sedentariness}

Two reviews addressed sedentariness. Uijtdewilligen et al127 looked at determinants of sedentariness by reviewing four prospective studies. They concluded for all determinants of sedentary behaviour insufficient evidence for both children and adolescents. Pate et al ${ }^{128}$ looked at correlates of sedentary behaviour and found that demographic, biological, psychosocial, environmental and behavioural factors have been studied as potential correlates of sedentary behaviour. From these studies, it was concluded that time spent in sedentary behaviour has been shown to be higher in lower socioeconomic groups, in older versus younger youth, in non-white youth, in more mature youth, and in young people who live in homes that present heavy exposure to electronic forms of entertainment (televisions and computers). In addition, several studies have shown that young people spend less time in sedentary behaviours if their parents set limits regarding time of participation in screen-based entertainment.

\section{Options for change: the evidence from intervention studies}

\section{PA promotion in community and family settings}

PA is influenced by a number of ecological levels, including the family and community environment. A limited evidence base is available on the effectiveness of PA promotion in young people in these settings. To update our knowledge on this topic, Van Sluijs et al ${ }^{129}$ conducted a review of reviews, as well as an updated systematic review from August 2007 to October 2010. Only 13 family and three community-based studies were identified in the three previous reviews combined, and all independently concluded that the evidence was limited in both family and community settings. Preliminary evidence, however, hinted that family-based interventions set in the home and including self-monitoring and goal setting may be a useful strategy to pursue. The updated literature search identified a further 10 intervention studies: six family-based and four community-based ones. Although more evaluations showed significant positive effects on PA (three family-based, one community-based studies), no distinctive characteristics of the effective interventions compared with those that were ineffective were identified when studying differences in intervention characteristics, target population or methodology. Based on the cumulative evidence to date, however, it also appears that creating safe environments in which young people can engage in free play or that they can use for active travel may have the potential to increase population levels of PA. Five studies showed positive effects on body composition, three of which were conducted on overweight or obese populations.

\section{PA promotion in school settings}

School-based interventions are thought to be the most universally applicable and effective way to counteract low PA and fitness since children and adolescents spend at least half of their waking hours in this setting. Kriemler et al ${ }^{130}$ performed a review of school-based interventions by applying a similar approach to Van Sluijs et al; that is, conducting an analysis of four reviews, as well as a systematic review on papers published between January 2007 and December 2010. The review of reviews led to the following conclusions: $47-65 \%$ of trials considered were found to be effective. The effect was mostly seen in school-related PA, while effects on outside school on overall PA were often not observed or not assessed. The school-based application of multicomponent intervention strategies was the most consistent promising intervention strategy, while controversy existed regarding the effectiveness of family involvement, focus on risk populations, or duration and intensity of the intervention. The current review included 20 trials. All of these trials showed a positive effect on in-school, out-of-school and in overall PA in 9/10 studies, and $55 \%$ of studies showed an increase in fitness. By taking the highest combined hierarchy level of quality and Public Health relevance (ie, objective assessment of overall PA), these studies all included children ( $\leq 12$ years) and applied multicomponent programmes with involvement of the families. While these results support the notion that school-based PA interventions are effective, time is ripe to look at long-term effects and implementation strategies.

\section{Context for action: potential solutions}

\section{The International Olympic Committee}

The IOC Congress in Copenhagen, 2010 outlined future priorities for the IOC emphasising the importance of sports participation from a public health perspective and protection of the health of the athlete through prevention of injuries and diseases. To promote PA effectively, the IOC acknowledges the need to care for the health problems of the active patient. This not only involves providing effective care for the injured patient, but also developing and promoting injury prevention measures actively. ${ }^{131}$ In 2010, the first Youth Olympic Games was held in Singapore emphasising culture, education and sports in 14-18-year-old athletes. During these Games, the athletes were exposed to educational tools developed by the IOC. Since 2005, the IOC has developed programmes for prevention of injuries and diseases in highlevel and recreational sports. Some examples are the IOC Periodic Health Exam, ${ }^{132}$ and protection of the child athlete, consensus meeting on training of the elite athlete ${ }^{133}$ and age determination. ${ }^{134}$

\section{International Federations}

Few International Federations (IFs) have programmes that address the issue of inactivity in young people and youth (unpublished survey of a selection of IFs 2010). Many IFs host Junior or Youth Championships. Other IFs have modified their sport to encourage youth participation. The Gymnastics Federation (FIG) is unique in that its athlete population is almost solely comprised of child and youth athletes. The Football Federation (FIFA) has published two studies on sport promotion in youth showing that football is as effective as an established obesity training programme for improving PA and fitness in young people. ${ }^{135} 136$ IFs can be instrumental in supporting National Federation programmes that address inactivity in youth.

\section{National Olympic Committees}

A few National Olympic Committees (NOCs) have developed programmes to promote PA and sport in young people. One example is the Canadian Olympic Committee, which developed an educational tool for students from grades 2 to 12. The Canadian Olympic School Program was designed in 
collaboration with physical health educators to support the development of a healthy, active, physically literate nation and to proactively combat the epidemic of physical inactivity in children and adolescents. The curriculum focuses on participation, effort and pride in the pursuit of excellence. This example illustrates the important role that NOCs can have in promoting PA and sport in youth. ${ }^{137}$

\section{The World Health Organization}

In 2010, the WHO and the IOC agreed to cooperate to ". . promote, physical activity and sport. .." The WHO Global Strategy on Diet, PA and Health (2004) and the WHO Global Action Plan for NCD prevention and Control (2008) provide a clear mandate for WHO's role in providing evidence-based recommendations, technical support, capacity building, surveillance and collaboration with United Nations (UN) agencies and international partners. In 2010, the WHO published the Global Recommendations on Physical Activity for Health, which includes recommendations for 5-17 year olds. The UN General Assembly high-level meeting on NCD prevention and control 2011 provides all stakeholders an opportunity to highlight the important impact PA and sport can have on the health of young people. ${ }^{138-140}$

\section{International PA networks}

There are two global and four regional PA promotion networks. Agita Mundo is the global network for PA promotion $^{141}$ and GAPA ${ }^{142}$ acts as the advocacy council of the International Society for Physical Activity and Health. The regional PA promotion networks are RAFA/PANA for the Americas, ${ }^{143}$ European Network for the Promotion of Healthenhancing Physical Activity (HEPA) for Europe, ${ }^{144}$ the AsiaPacific Physical Activity Network ${ }^{145}$ and the African Physical Activity Network. ${ }^{146}$

These networks can play a crucial role in promoting the health and fitness of young people in several ways: by providing exchange platforms and access to key experts; by analysing practice-led evidence to identify good practice, develop guidance and foster monitoring and evaluation ${ }^{147}$; by distributing recommendations to expert communities and local implementers; and by contributing to more effective dissemination of recommendations and good practice regionally, nationally or locally. However, availability of practice-led evidence has so far been non-systematic. While these networks have become instrumental platforms for exchange, their scope and reach is constrained by limited funding as they depend largely on voluntary contributions.

\section{Non-governmental organizations}

Non-governmental organizations (NGOs) use PA and sport as platforms to develop social capital and social cohesion. ${ }^{148} 149$ NGOs involved in Sports for All (http://www.tafisa.net) and Sports for Development (http://www.sportanddev.org) identified health as one key outcome. ${ }^{149}$ The right to 'participate in sport, physical activity or play' are considered fundamental human rights. ${ }^{150} 151$

NGOs raise funds, educate, mentor, advocate, implement programmes, and develop local capacity. ${ }^{152}$ These organisations use the vehicle of sports participation as a platform in the fight against HIV/AIDS, tuberculosis and malaria in the developing world and to promote PA in other settings. 135153

There is, however, limited central coordination to promote interagency cooperation and inadequate evaluation of programme implementation. Evaluation needs to be planned early and adapted to local realities. NGO partnerships must ensure sustainability, equity, appropriate allocation of resources and community participation. ${ }^{154}$

\section{Governments}

Reviews of actions taken by governments in many countries show mixed results in terms of operationalised plans for sports and PA promotion for young people. Lessons learned from one programme, the Agita Galera Program, which deals with 6000 schools, and about 6 million students, in the State of São Paulo, Brazil, provided an opportunity for the government to identify and promote PA and sports participation, a surveillance system, and support for building partnerships; to build infrastructures for sports participation; to facilitate the development and implementation of an 'Active-School Curriculum'; to promote active transport to school; and to incentivise the practice of PA and sports inside and outside school. ${ }^{155}$

\section{Education}

Health and fitness promotion via PA represents a complex issue, which can only be resolved by multisectoral interventions because no one sector can independently resolve the challenges involved. The education sector, in general, and physical education (PE), in particular, comprise a primacy setting for interventions throughout formative development, which can influence positive attitudes and behaviours of young people during compulsory school attendance years.

PE makes a unique contribution to education through the development of 'physical and health literacy'. Together, they seek to help pupils develop the necessary skills to make healthy choices and are key in sowing the seeds in the formation of the physically educated person. Physical movement education is the only educational experience where the focus is on the body, its movement and physical development, and it helps young people to learn to respect and to value their own bodies and abilities, and those of others.

A school's role extends to encouraging young people to continue participation in PA, through the provision of links and co-ordinated opportunities for all young people at all levels. Schools should also develop partnerships with the wider community (health and sport) to extend and improve the opportunities available for students to remain physically active: bridges need to be built and pathways created to foster partnerships and so increase the potential for positive interventions.

Comprehensive whole-of-school approaches to child health represent an effective strategy to address childhood physical inactivity. ${ }^{156-161}$ Successful models incorporate strategies across settings, emphasise partnerships and advocate political and financial support. Factors deemed key to success are political will, sustained funding, shared vision and decisionmaking, policy, evaluation and teacher training and support, multiple components, adaptability and compatibility.

Implementation of effective school-based models in the realworld setting is complex and demands a multipartner investment over the long term. Ecological approaches that integrate government, schools, the community, individuals and settings are likely the key to successful and sustained implementation. ${ }^{157} 160-163$

There is a gap between demonstrating the effectiveness of PA interventions and our understanding of the wide-scale implementation and/or dissemination of them. ${ }^{163}$

\section{Healthcare system}

The healthcare setting can play an important role for promotion of PA, fitness and health in adults. ${ }^{164-166}$ The few healthcarebased studies to date that have addressed young people have 
dealt with exercise groups, counseling and computer-based behaviour change programmes. ${ }^{164}$ The scientific evidence is insufficient to draw any conclusions about how these methods affect PA among young people. That said, PA is regarded as a cornerstone in the treatment of common child and adolescent diseases. ${ }^{167168}$ Through the provision of adequate education of primary healthcare professionals on the benefits and prescription of PA, the healthcare system can play an important role in the promotion of PA and sport involvement in young people.

\section{Summary and recommendations}

To realise Recommendation \#<51> from the Olympic Movement in Society Congress (Copenhagen 2009), a coordinated, collaborative, global effort involving many stakeholders, including members of the Olympic Movement, is required. It is essential for the success of future programmes that young people are involved to plan, implement, deliver and evaluate sport and PA programmes. The following recommendations are formulated based on a review of the current scientific evidence and the collective expertise of the authors in their respective fields relating to the health and fitness of young people.

\section{Sport organisations}

Sport organisations have a role to play in the realisation of the global recommendations for young people to accumulate at least 60 min per day of moderate-to-vigorous intensity PA in addition to the activity they accrue as part of everyday living.

It is recommended that sport organisations strengthen their role in the promotion of PA and sport for health and fitness in youth in the following ways:

- ensure that sport programmes include youth-oriented activities to engage and retain young athletes;

- educate sport coaches to incorporate appropriate healthrelated fitness training in relation to growth and maturation;

- identify and lower the barriers to participation in sport;

- collaborate with youth, parents, school personnel and community programmes to design and deliver sports programmes that attract and retain young people;

- foster collaboration with international, regional and national PA promotion networks;

- evaluate and improve the quality and delivery of sport programmes for young developing athletes; and

- encourage research into the efficacy and effectiveness of delivery of sport and PA for young people.

\section{Governments}

It is recommended that governments:

- advocate PA and health promotion on global health and regional agency agendas;

- foster collaboration with international, regional and national PA promotion networks;

- place health and PA higher on the national political agenda;

- develop, implement and evaluate policy to promote sport and PA in young people;

- enhance funding for youth involvement in sport and PA programmes across sectors;

- support multisectoral policies and provision of school-wider community (sport, recreation, health agencies) partnerships to improve PA opportunities for young people;

- ensure that providers of recreational programmes for young people limit the time spent in sedentary pursuits such as television watching, video game playing and computer use; and

- support research to better understand the role of PA in the health trends of young people.
Educational system: With regard to the educational system, it is recommended that governments:

- provide effective PE in school delivered by qualified professionals at all levels of the curriculum;

- provide a minimum of three lessons of PE totaling 120-180 min per week;

- ensure that opportunities for PE/PA are provided in a variety of settings and are embedded within the curriculum;

- collaborate with community organisations to create accessible and safe PA and sport environments;

- implement adaptable whole-of-school models that utilise multiple component strategies and routes of entry; and

- allocate adequate resources to PE/PA programmes.

Healthcare System: With regard to the healthcare system, it is recommended that governments:

- provide mandatory education of healthcare professionals on the benefits and prescription of PA for young people;

- increase collaboration between healthcare professionals and other providers of PA and sport in the community; and

- revise the healthcare financing system to include reimbursement for individualised life style counseling and follow-up.

\section{Non-governmental organisations}

It is recommended that:

- Sport for Development programmes be evaluated for the efficacy of health outcomes and impact;

- a registry of NGOs, both sport and non-sport, be established to promote PA and sport as a vehicle for health and community development; and

- NGOs develop a filter for partnerships to ensure sustainability, equity, allocation of resources, community ownership and buy-in, and to limit unintended consequences of PA and sport programming.

\section{Research recommendations}

It is recommended that research be conducted:

- with respect to sport, to assess if

$\triangleright$ current structures of organised sport are adequate to meet the needs of young people and

$\triangleright$ coaches are adequately prepared to cope with the unique pedagogical physiological and psychological needs of young people during growth and development;

- to use new non-invasive technologies such as MRI and spectroscopy and near-infrared spectroscopy to better understand responses to exercise and young people's fitness during growth and maturation;

- to evaluate setting and types of young people's habitual PA, sport participation and fitness through large-scale, standardised, national and international surveys;

- to evaluate the effect of PA promotion interventions on intermediate factors, and at long-term follow-up with objective measures of the behaviour, fitness and health outcomes;

- to better define the dose-response mechanisms and effects of PA/exercise and sedentary behaviour on fitness and health during growth and development;

- to assess which method of PA promotion is best for a given population taking into consideration factors such as disease state, socioeconomic conditions, culture, ethnicity, gender and age;

- to assess reach and implementation issues beyond attendance rates in intervention studies to establish the potential for wider implementation; and 
- to use objective measures of PA whenever possible to enhance the quality of assessment and interpretation of data.

It is recommended that a web-based repository for surveillance data on objectively measured PA be developed to better compile, evaluate and disseminate the scientific evidence in this field.

\section{REVIEWS INFORMING THE CONSENSUS STATEMENT}

Armstrong N, Tomkinson G, Ekelund U. Aerobic fitness and its relationship to sport, exercise training and habitual physical activity during youth. Br J Sports Med 2011. Biddle S, Asare M. Physical activity and mental health in children and adolescents: A Review of Reviews. Br J Sports Med 2011.

Bo Andersen L, Riddoch C, Kriemler S, Hills A. Physical activity and cardiovascular risk factors in children. Br J Sport Med 2011.

Boreham C, McKay H. Physical activity and bone health. Br J Sports Med 2011. Carter C, Micheli L. Training the child athlete: Inadequate physical fitness is a risk factor for injury. Br J Sports Med 2011

Ekelund U, Tomkinson G, Armstrong N. What Proportion of Youth Are Physically Active? Measurement Issues, Levels and Recent Time Trends. Br J Sports Med 2011 Hills A, Bo Andersen L, Byrne N. Physical activity and obesity in children. Br J Sports Med 2011.

Kriemler S, Meyer U, Martin E, van Sluijs E, Andersen LB, Martin B. Effect of schoolbased interventions on physical activity and fitness in children and adolescents: A review of reviews and systematic update. Br J Sports Med 2011.

Micheli L, Ljungqvist A, Mountjoy M, Armstrong T, Kahlmeier S, Matsudo V, Lambert V, Harman K, McKay H, Sundberg C. Fitness and health of young people through sport: The context for action. Br J Sports Med 2011.

Pate R, Mitchell J, Byun W, Dowda M. Sedentary behaviour in youth. Br J Sports Med 2011. Uijtdewilligen L, Nauta J, Singh A, van Mechelen W, Twisk J, vander Horst K, Chinapaw M. Determinants of physical activity and sedentary behavior in young people: A review and quality synthesis of prospective studies. Br J Sports Med 2011. Van Sluijs E, Kriemler S, McMinn A. Options for changing young people's physical activity levels - evidence from community and family interventions. Br J Sports Med 2011.

Contributors All authors contributed to the writing of this Statement. MM - Intro/scope/International Federations/NOC/recommendations (Primary Author); LBA - Cardiovascular/recommendations; NA - Are children fit/ active/ recommendations (Section Editor); SB - Psych/recommendations; CB - Bone/ recommendations; H-PBB - Correlates/recommendations; UE - Are children active/ recommendations; LE - IOC contribution/recommendations; $\mathrm{KH}-$ Education/ recommendations; $\mathrm{AH}$ - Obese/recommendations; SoK - International agencies/recommendations; SuK - School based interventions/recommendations: $\mathrm{EL}-\mathrm{NGO} /$ recommendations; $\mathrm{AL}-\mathrm{IOC}$ / recommendations;

VM - Governments/ recommendations; HMcK - Education/ Bone/ recommendations; LM - Injury risk/ recommendations (Section Editor): $\mathrm{RP}$ - Correlates sedentary/ recommendations; CR - Health risks inactivity/ Recommendations; PS - IOC contribution/ recommendations; CJS - Health care sector/ recommendations; GT - Are children fit/active/recommendations; EvS - Community based interventions/recommendations; WvM - Correlates activity/sedentary/ Recommendations (Section Editor).

Acknowledgements The group acknowledges the contribution of Tim Armstrong from the WHO during the IOC Consensus Meeting.

\section{Competing interests None.}

Provenance and peer review Commissioned; internally peer reviewed.

\section{Author affiliations}

${ }^{1}$ IOC Medical Commission, Lausanne, Switzerland

${ }^{2}$ McMaster University, Hamilton, Canada

${ }^{3}$ Institute of Sport Sciences and Clinical Biomechanics, University of Southern

Denmark, Odense, Denmark

${ }^{4}$ Children's Health and Exercise Research Centre, University of Exeter, Exeter, UK

${ }^{5}$ School of Sport, Exercise \& Health Sciences Loughborough University,

Loughborough, UK

${ }^{6}$ Institute for Sport and Health, University College, Dublin, Ireland

${ }^{7}$ University of Paderborn, Paderborn, Germany

${ }^{8}$ Medical Research Council Epidemiology Unit, Cambridge, UK

${ }^{9}$ School of Health and Medical Sciences, Orebro University, Orebro, Sweden

${ }^{10}$ Oslo Sports Trauma Research Center, Norwegian School of Sport Sciences, Oslo,

Norway

${ }^{11}$ Institute of Sport and Exercise Science, University of Worcester, Worcester, UK

${ }^{12}$ Griffith University and Mater Medical Research Institute (MMRI), Brisbane, Queensland, Australia

${ }^{13}$ Physical Activity and Health Unit, Institute of Social and Preventive Medicine, University of Zurich, Zurich, Switzerland

${ }^{14}$ Swiss Tropical and Public Health Institute, University of Basel, Basel, Switzerland

${ }^{15}$ UCT/MRC Research Unit for Exercise Science and Sports Medicine, University of

Cape Town, Cape Town, South Africa
${ }^{16}$ Physical Fitness Research Laboratory, Sao Paolo, Brazil

${ }^{17} \mathrm{Centre}$ for Hip Health and Mobility and Faculty of Medicine, University of British Columbia, Vancouver, British Columbia, Canada

${ }^{18}$ Harvard Medical School, Boston, Massachusetts, USA

${ }^{19}$ Arnold School of Public Health, University of South Carolina, Columbia, South

Carolina, USA

${ }^{20}$ Sport, Health and Exercise Science, University of Bath, Bath, UK

${ }^{21}$ Molecular Exercise Physiology, Department of Physiology and Pharmacology,

Karolinska Institutet, Stockholm, Sweden

${ }^{22}$ Health and Use of Time (HUT) Group, Sansom Institute for Health Research,

University of South Australia, Adelaide, South Australia, Australia

${ }^{23}$ Medical Research Council Epidemiology Unit and UKCRC Centre of Excellence in

Diet and Activity Reserach (CEDAR), Cambridge, UK

${ }^{24}$ Department of Occupational and Sports Medicine and EMGO Institute for Health and Care Research, VU University Medical Center, Amsterdam, The Netherlands

\section{REFERENCES}

1. The Olympic Movement in Society. Proceedings from the XIII Olympic Congress. Recommendations of Theme 'Olympism and Youth'. Olympic Congress 2009. Copenhagen, Demark, 2009.

2. World Health Organization. Global Status Report on Noncommunicable Diseases 2010. Description of the Global Burden of NCDs, Their Risk Factors and Determinants. Geneva: World Health Organization, 2011.

3. World Health Organization. Global Health Risks: Mortality and Burden of Disease Attributable to Selected Major Risks. Geneva, World Health Organization, 2009.

4. Riddoch CJ, Mattocks C, Deere K, et al. Objective measurement of levels and patterns of physical activity. Arch Dis Child 2007;92:963-9.

5. Janssen I, Leblanc AG. Systematic review of the health benefits of physical activity and fitness in school-aged children and youth. Int J Behav Nutr Phys Act 2010; 7:40.

6. Nader PR, Bradley RH, Houts RM, et al. Moderate-to-vigorous physical activity from ages 9 to 15 years. JAMA 2008;300:295-305.

7. Biddle SJ, Pearson N, Ross GM, et al. Tracking of sedentary behaviours of young people: a systematic review. Prev Med 2010;51:345-51.

8. Janz KF, Dawson JD, Mahoney LT. Tracking physical fitness and physical activity from childhood to adolescence: the muscatine study. Med Sci Sports Exerc 2000;32:1250-7.

9. Jiménez-Pavón D, Kelly J, Reilly JJ. Associations between objectively measured habitual physical activity and adiposity in children and adolescents: systematic review. Int J Pediatr Obes 2010;5:3-18.

10. Reichert FF, Baptista Menezes AM, Wells JC, et al. Physical activity as a predictor of adolescent body fatness: a systematic review. Sports Med 2009;39:279-94.

11. Dencker M, Andersen LB. Health-related aspects of objectively measured daily physical activity in children. Clin Physiol Funct Imaging 2008;28:133-44.

12. LaMonte MJ, Blair SN. Physical activity, cardiorespiratory fitness, and adiposity: contributions to disease risk. Curr Opin Clin Nutr Metab Care 2006;9:540-6.

13. Tremblay MS, Colley RC, Saunders TJ, et al. Physiological and health implications of a sedentary lifestyle. Appl Physiol Nutr Metab 2010;35:725-40.

14. Corder K, Ekelund U, Steele RM, et al. Assessment of physical activity in youth J Appl Physiol 2008;105:977-87.

15. Adamo KB, Prince SA, Tricco AC, et al. A comparison of indirect versus direct measures for assessing physical activity in the pediatric population: a systematic review. Int J Pediatr Obes 2009;4:2-27.

16. Chinapaw MJ, Mokkink LB, van Poppel MN, et al. Physical activity questionnaires for youth: a systematic review of measurement properties. Sports Med 2010;40:539-63.

17. Steele RM, Brage S, Corder K, et al. Physical activity, cardiorespiratory fitness, and the metabolic syndrome in youth. J Appl Physiol 2008;105:342-51.

18. Reilly JJ, Penpraze V, Hislop J, et al. Objective measurement of physical activity and sedentary behaviour: review with new data. Arch Dis Child 2008; 93:614-19

19. Sisson SB, Katzmarzyk PT. International prevalence of physical activity in youth and adults. Obes Rev 2008; 9:606-14.

20. Li S, Treuth MS, Wang Y. How active are American adolescents and have they become less active? Obes Rev 2010;11:847-62.

21. Troiano RP, Berrigan D, Dodd KW, et al. Physical activity in the United States measured by accelerometer. Med Sci Sports Exerc 2008;40:181-8.

22. Wickel EE, Eisenmann JC. Contribution of youth sport to total daily physical activity among 6- to 12-yr-old boys. Med Sci Sports Exerc 2007;39:1493-500.

23. Møller NC, Kristensen PL, Wedderkopp N, et al. Objectively measured habitual physical activity in 1997/1998 vs 2003/2004 in Danish children: the European Youth Heart Study. Scand J Med Sci Sports 2009;19:19-29.

24. Raustorp A, Ekroth Y. Eight-year secular trends of pedometer-determined physical activity in young Swedish adolescents. J Phys Act Health 2010;7:369-74.

25. Ekelund U, Tomkinson GR, Armstrong N. What Proportion of Youth Are Physically Active? Measurement Issues, Levels and Recent Time Trends. Br J Sports Med 2011;45:859-5. 
26. Armstrong $\mathbf{N}$, Welsman JR. Peak oxygen uptake in relation to growth and maturation in 11- to 17-year-old humans. Eur J Appl Physiol 2001;85:546-51.

27. Baxter-Jones A, Goldstein H, Helms P. The development of aerobic power in young athletes. J Appl Physiol 1993;75:1160-7.

28. Fawkner SG, Armstrong N, Potter CR, et al. Oxygen uptake kinetics in children and adults after the onset of moderate-intensity exercise. J Sports Sci 2002;20:319-26.

29. Fawkner SG, Armstrong N. Longitudinal changes in the kinetic response to heavy-intensity exercise in children. J App/ Physiol 2004;97:460-6.

30. Armstrong $\mathbf{N}$, Barker AR. Endurance training and elite young athletes. Med Sport Sci 2011;56:59-83.

31. Kemper H, Koppes L. Is physical activity important for aerobic power in young males and females? In: Kemper H, ed. Amsterdam Growth and Health Longitudinal Study. Basel: Karger 2004:153-66.

32. Armstrong N, McManus A, Welsman J. Aerobic fitness. In: Armstrong N, Van Mechelen W, eds. Paediatric Exercise Science and Medicine. Second edition. Oxford: Oxford University Press 2008:269-82.

33. Tomkinson GR, Olds TS. Secular changes in pediatric aerobic fitness test performance: the global picture. Med Sport Sci 2007;50:46-66.

34. Armstrong N, Tomkinson GR, Ekelund U. Aerobic fitness and its relationship to sport, exercise training and habitual physical activity during youth. Br J Sports Med 2011;45:849-58.

35. Strong WB, Malina RM, Blimkie CJ, et al. Evidence based physical activity for school-age youth. J Pediatr 2005;146:732-7.

36. McMurray R, Andersen L. The influence of exercise on the metabolic syndrome in youth: a review. Am J Lifestyle Med 2010;4:176-86.

37. Kelley GA, Kelley KS, Tran ZV. The effects of exercise on resting blood pressure in children and adolescents: a meta-analysis of randomized controlled trials. Prev Cardiol 2003;6:8-16

38. Ewart CK, Young DR, Hagberg JM. Effects of school-based aerobic exercise on blood pressure in adolescent girls at risk for hypertension. Am J Public Health 1998;88:949-51.

39. Danforth JS, Allen KD, Fitterling JM, et al. Exercise as a treatment for hypertension in low-socioeconomic-status black children. J Consult Clin Psychol 1990;58:237-9.

40. Hansen HS, Froberg K, Hyldebrandt N, et al. A controlled study of eight months of physical training and reduction of blood pressure in children: the Odense schoolchild study. BMJ 1991;303:682-5.

41. Hagberg JM, Goldring D, Ehsani AA, et al. Effect of exercise training on the blood pressure and hemodynamic features of hypertensive adolescents. Am J Cardiol 1983:52:763-8

42. Hagberg JM, Ehsani AA, Goldring D, et al. Effect of weight training on blood pressure and hemodynamics in hypertensive adolescents. J Pediatr 1984:104:147-51.

43. Bell LM, Watts K, Siafarikas A, et al. Exercise alone reduces insulin resistance in obese children independently of changes in body composition. J Clin Endocrinol Metab 2007;92:4230-5.

44. Jago R, Jonker ML, Missaghian M, et al. Effect of 4 weeks of Pilates on the body composition of young girls. Prev Med 2006;42:177-80.

45. Andersen LB. Blood pressure, physical fitness and physical activity in 17-yearold Danish adolescents. J Intern Med 1994:236:323-9.

46. Nielsen GA, Andersen LB. The association between high blood pressure, physical fitness, and body mass index in adolescents. Prev Med 2003;36:229-34.

47. Andersen LB, Harro M, Sardinha LB, et al. Physical activity and clustered cardiovascular risk in children: a cross-sectional study (The European Youth Heart Study). Lancet 2006;368:299-304.

48. Dobbins M, De Corby K, Robeson P, et al. School-based physical activity programs for promoting physical activity and fitness in children and adolescents aged 6-18. Cochrane Database Syst Rev 2009:1:CD007651.

49. Lau PCW, Yu CW, Lee A, et al. The physiological and psychological effects of resistance training on Chinese obese adolescents. J Exerc Sci Phys Fit 2004:2:115-20.

50. de Ferranti SD, Gauvreau K, Ludwig DS, et al. Prevalence of the metabolic syndrome in American adolescents: findings from the Third National Health and Nutrition Examination Survey. Circulation 2004;110:2494-7.

51. Weiss R, Dziura J, Burgert TS, et al. Obesity and the metabolic syndrome in children and adolescents. N Eng/ J Med 2004;350:2362-74.

52. Jolliffe CJ, Janssen I. Development of age-specific adolescent metabolic syndrome criteria that are linked to the Adult Treatment Panel III and International Diabetes Federation criteria. J Am Coll Cardiol 2007:49:891-8.

53. Ford ES, Ajani UA, Mokdad AH. The metabolic syndrome and concentrations of C-reactive protein among U.S. youth. Diabetes Care 2005;28:878-81.

54. Pan Y, Pratt CA. Metabolic syndrome and its association with diet and physical activity in US adolescents. J Am Diet Assoc 2008;108:276-86.

55. Rizzo NS, Ruiz JR, Hurtig-Wennlöf A, et al. Relationship of physical activity, fitness, and fatness with clustered metabolic risk in children and adolescents: the European youth heart study. J Pediatr 2007;150:388-94.

56. Stergioulas A, Tripolitsioti A, Messinis D, et al. The effects of endurance training on selected coronary risk factors in children. Acta Paediatr 1998:87:401-4.
57. Ferguson MA, Gutin B, Le NA, et al. Effects of exercise training and its cessation on components of the insulin resistance syndrome in obese children. Int $J$ Obes Relat Metab Disord 1999:23:889-95.

58. Heyman E, Toutain C, Delamarche P, et al. Exercise training and cardiovascular risk factors in type 1 diabetic adolescent girls. Pediatr Exerc Sci 2007:19:408-19.

59. Meyer AA, Kundt G, Lenschow U, et al. Improvement of early vascular changes and cardiovascular risk factors in obese children after a six-month exercise program. J Am Coll Cardiol 2006;48:1865-70.

60. Benson AC, Torode ME, Fiatarone Singh MA. A rationale and method for highintensity progressive resistance training with children and adolescents. Contemp Clin Trials 2007;28:442-50.

61. García-Artero E, Ortega FB, Ruiz JR, et al. [Lipid and metabolic profiles in adolescents are affected more by physical fitness than physical activity (AVENA study)]. Rev Esp Cardiol 2007:60:581-8.

62. Janz KF, Dawson JD, Mahoney LT. Increases in physical fitness during childhood improve cardiovascular health during adolescence: the Muscatine Study. Int J Sports Med 2002;23(Suppl 1):S15-21.

63. Khosla S, Melton LJ 3rd, Dekutoski MB, et al. Incidence of childhood distal forearm fractures over 30 years: a population-based study. JAMA 2003;290:1479-85.

64. Goulding A, Jones IE, Taylor RW, et al. More broken bones: a 4-year double cohort study of young girls with and without distal forearm fractures. J Bone Miner Res 2000:15:2011-18.

65. US Department of Health and Human Services. Bone Health and Osteoporosis: A Report of the Surgeon General. Rockville, MD: US Department of Health and Human Services, Office of the Surgeon General, 2004.

66. Daly RM, Petit MA, eds. Optimising bone mass and strength: the role of physical activity and nutrition during growth. Med Sport Sci 2007;51:1-10

67. Macdonald H, Ashe M, McKay H. The link between physical activity and bone strength across the lifespan. Int J Clin Rheum 2009;4:437-63.

68. Macdonald H, Burrows M, McKay H. Physical activity and skeletal growth. In: Orwoll E, Bilezikian J, Vanderschueren D, eds. Osteoporosis in Men: The Effects of Gender on Skeletal Health. Second edition. San Diego, CA: Elsevier 2009:131-46.

69. Rizzoli R, Bianchi ML, Garabédian M et al. Maximizing bone mineral mass gain during growth for the prevention of fractures in the adolescents and the elderly. Bone 2010:46:294-305.

70. Nikander R, Sievänen H, Heinonen A, et al. Targeted exercise against osteoporosis: a systematic review and meta-analysis for optimising bone strength throughout life. BMC Med 2010;8:47

71. Robling AG, Hinant FM, Burr DB, et al. Improved bone structure and strength after long-term mechanical loading is greatest if loading is separated into short bouts. J Bone Miner Res 2002;17:1545-54.

72. Courteix D, Lespessailles E, Peres SL, et al. Effect of physical training on bone mineral density in prepubertal girls: a comparative study between impact-loading and non-impact-loading sports. Osteoporos Int 1998:8:152-8.

73. Vicente-Rodriguez G, Jimenez-Ramirez J, Ara I, et al. Enhanced bone mass and physical fitness in prepubescent footballers. Bone 2003;33:853-9.

74. Ward KA, Roberts SA, Adams JE, et al. Bone geometry and density in the skeleton of pre-pubertal gymnasts and school children. Bone 2005:36:1012-18.

75. Matthews BL, Bennell KL, McKay HA, et al. Dancing for bone health: a 3-year longitudinal study of bone mineral accrual across puberty in female non-elite dancers and controls. Osteoporos Int 2006:17:1043-54.

76. Kannus $\mathbf{P}$, Haapasalo H, Sankelo M, et al. Effect of starting age of physical activity on bone mass in the dominant arm of tennis and squash players. Ann Intern Med 1995;123:27-31.

77. Kontulainen S, Sievänen H, Kannus P, et al. Effect of long-term impact-loading on mass, size, and estimated strength of humerus and radius of female racquetsports players: a peripheral quantitative computed tomography study between young and old starters and controls. J Bone Miner Res 2002;17:2281-9.

78. Hind K, Burrows M. Weight-bearing exercise and bone mineral accrual in children and adolescents: a review of controlled trials. Bone 2007:40:14-27.

79. Macdonald HM, Kontulainen SA, Khan KM, et al. Is a school-based physical activity intervention effective for increasing tibial bone strength in boys and girls? J Bone Miner Res 2007;22:434-46.

80. Daly $\mathbf{R}$. The effect of exercise on bone structural geometry during growth. In: Daly R, Petit M, eds. Optimizing Bone Mass and Strength: The Role of Physical Activity and Nutrition During Growth. Med Sport Sci 2007:51:33-49.

81. Tobias JH, Steer CD, Mattocks CG, et al. Habitual levels of physical activity influence bone mass in 11-year-old children from the United Kingdom: findings from a large population-based cohort. J Bone Miner Res 2007:22:101-9.

82. Janz KF, Letuchy EM, Eichenberger Gilmore JM, et al. Early physical activity provides sustained bone health benefits later in childhood. Med Sci Sports Exerc 2010;42:1072-8

83. Pettersson U, Nilsson M, Sundh V, et al. Physical activity is the strongest predictor of calcaneal peak bone mass in young Swedish men. Osteoporos Int 2010:21:447-55

84. McKay H, Smith E. Winning the battle against childhood physical inactivity: the key to bone strength? J Bone Miner Res 2008:23:980-5. 
85. Warden SJ, Fuchs RK, Castillo AB, et al. Exercise when young provides lifelong benefits to bone structure and strength. J Bone Miner Res 2007;22:251-9.

86. Gunter K, Baxter-Jones AD, Mirwald RL, et al. Impact exercise increases BMC during growth: an 8-year longitudinal study. J Bone Miner Res 2008;23:986-93.

87. Khan KM, Bennell KL, Hopper JL, et al. Self-reported ballet classes undertaken at age 10-12 years and hip bone mineral density in later life. Osteoporos Int 1998;8:165-73.

88. Bass S, Pearce G, Bradney M, et al. Exercise before puberty may confer residual benefits in bone density in adulthood: studies in active prepubertal and retired female gymnasts. J Bone Miner Res 1998;13:500-7.

89. Beck TJ, Petit MA, Wu G, et al. Does obesity really make the femur stronger? BMD, geometry, and fracture incidence in the women's health initiativeobservational study. J Bone Miner Res 2009;24:1369-79.

90. Lobstein T, Baur L, Uauy R. Obesity in children and young people: a crisis in public health. Obes Rev 2004;5(Suppl 1):4-104.

91. Wang $\mathbf{Y}$, Lobstein T. Worldwide trends in childhood overweight and obesity. Int J Pediatr Obes 2006;1:11-25

92. Hills AP, King NA, Armstrong TP. The contribution of physical activity and sedentary behaviours to the growth and development of children and adolescents: implications for overweight and obesity. Sports Med 2007;37:533-45.

93. Colley R, Garriguet D, Janssen I, et al. Physical activity of Canadian children and youth: accelerometer results from the 2007 to 2009 Canadian Health Measures Survey. Health Rep 2011;22:1-9.

94. Sallis JF, Glanz K. Physical activity and food environments: solutions to the obesity epidemic. Milbank 0 2009;87:123-54.

95. Ding EL, Hu FB. Commentary: relative importance of diet vs physical activity for health. Int J Epidemiol 2010;39:209-11.

96. Hills AP, Okely AD, Baur LA. Addressing childhood obesity through increased physical activity. Nat Rev Endocrinol 2010;6:543-9.

97. Larun L, Nordheim LV, Ekeland E, et al. Exercise in prevention and treatment of anxiety and depression among children and young people. Cochrane Database Syst Rev 2006;3:CD004691.

98. Ekeland E, Heian F, Hagen $\mathrm{K}$, et al. Exercise to improve self-esteem in children and young people. Cochrane Database Syst Rev 2004;1:CD003683.

99. Keeley T, Fox K. The impact of physical activity and fitness on academic achievement and cognitive performance in children. Int Rev Sport Exerc Psychol 2009;2:198-214

100. Primack BA, Swanier B, Georgiopoulos AM, et al. Association between media use in adolescence and depression in young adulthood: a longitudinal study. Arch Gen Psychiatry 2009:66:181-8.

101. Comstock R, Knox C, Yard E, et al. Sports-related injuries among high school athletes - United States, 2005-06 school year. CDC MMWR 2006;55:1037-40

102. Smith A, Andrish J, Micheli L. The prevention of sports injuries of children and adolescents. Med Sci Sports Exerc 1993;25:1-7.

103. Emery CA. Injury prevention and future research. Med Sport Sci 2005;48:179-200

104. Emery CA. Risk factors for injury in child and adolescent sport: a systematic review of the literature. Clin J Sport Med 2003:13:256-68.

105. Faigenbaum AD, Myer GD. Resistance training among young athletes: safety, efficacy and injury prevention effects. Br J Sports Med 2010;44:56-63.

106. Renstrom $\mathbf{P}$, Ljungqvist $A$, Arendt $E$, et al. Non-contact $A C L$ injuries in female athletes: an International Olympic Committee current concepts statement. Br J Sports Med 2008;42:394-412.

107. Hübscher M, Zech A, Pfeifer K, et al. Neuromuscular training for sports injury prevention: a systematic review. Med Sci Sports Exerc 2010;42:413-21.

108. Emery CA, Cassidy JD, Klassen TP, et al. Effectiveness of a home-based balancetraining program in reducing sports-related injuries among healthy adolescents: a cluster randomized controlled trial. CMAJ 2005;172:749-54.

109. Emery CA, Rose MS, McAllister JR, et al. A prevention strategy to reduce the incidence of injury in high school basketball: a cluster randomized controlled trial. Clin J Sport Med 2007;17:17-24.

110. OIsen $\mathbf{0 E}$, Myklebust G, Engebretsen L, et al. Exercises to prevent lower limb injuries in youth sports: cluster randomised controlled trial. BMJ 2005;330:449.

111. Soligard T, Myklebust G, Steffen K, et al. Comprehensive warm-up programme to prevent injuries in young female footballers: cluster randomised controlled trial. BMJ 2008;337:a2469.

112. Cahill BR, Griffith EH. Effect of preseason conditioning on the incidence and severity of high school football knee injuries. Am J Sports Med 1978;6:180-4

113. Heidt RS Jr, Sweeterman LM, Carlonas RL, et al. Avoidance of soccer injuries with preseason conditioning. Am J Sports Med 2000;28:659-62.

114. Edlich RF, Swainston EM, Dahlstrom JJ, et al. An injury prevention program to prevent gymnastic injuries in children and teenagers. J Environ Pathol Toxicol Oncol 2010;29:13-15.
115. Hewett TE, Lindenfeld TN, Riccobene JV, et al. The effect of neuromuscular training on the incidence of knee injury in female athletes. A prospective study. Am J Sports Med 1999;27:699-706.

116. Mandelbaum BR, Silvers HJ, Watanabe DS, et al. Effectiveness of a neuromuscular and proprioceptive training program in preventing anterior cruciate ligament injuries in female athletes: 2-year follow-up. Am J Sports Med 2005;33:1003-10.

117. Markovic G, Mikulic P. Neuro-musculoskeletal and performance adaptations to lower-extremity plyometric training. Sports Med 2010;40:859-95

118. Alentorn-Geli E, Myer GD, Silvers HJ, et al. Prevention of non-contact anterior cruciate ligament injuries in soccer players. Part 2: a review of prevention programs aimed to modify risk factors and to reduce injury rates. Knee Surg Sports Traumatol Arthrosc 2009;17:859-79.

119. Elliot DL, Goldberg L, Kuehl KS. Young women's anterior cruciate ligament injuries: an expanded model and prevention paradigm. Sports Med 2010;40:367-76

120. Verhagen $\mathbf{E}$, van $\operatorname{der}$ Beek A, Twisk J, et al. The effect of a proprioceptive balance board training program for the prevention of ankle sprains: a prospective controlled trial. Am J Sports Med 2004;32:1385-93.

121. McGuine TA, Keene JS. The effect of a balance training program on the risk of ankle sprains in high school athletes. Am J Sports Med 2006;34:1103-11.

122. McHugh MP, Tyler TF, Mirabella MR, et al. The effectiveness of a balance training intervention in reducing the incidence of noncontact ankle sprains in high school football players. Am J Sports Med 2007;35:1289-94.

123. Bahr R, Lian 0, Bahr IA. A twofold reduction in the incidence of acute ankle sprains in volleyball after the introduction of an injury prevention program: a prospective cohort study. Scand J Med Sci Sports 1997;7:172-7.

124. Waterman BR, Owens BD, Davey S, et al. The epidemiology of ankle sprains in the United States. J Bone Joint Surg Am 2010;92:2279-84.

125. Collard DC, Verhagen EA, Chinapaw MJ, et al. Effectiveness of a school-based physical activity injury prevention program: a cluster randomized controlled trial. Arch Pediatr Adolesc Med 2010:164:145-50.

126. Collard DC, Chinapaw MJ, van Mechelen W, et al. Design of the iPlay study: systematic development of a physical activity injury prevention programme for primary school children. Sports Med 2009;39:889-901.

127. Uijtdewilligen L, Nauta J, Singh A, et al. Determinants of physical activity and sedentary behavior in young people: a review and quality synthesis of prospective studies. Br J Sports Med 2011;45:896-905.

128. Pate R, Mitchell J, Byun W, et al. Sedentary behaviour in youth. Br J Sports Med 2011:45:906-13.

129. Van Sluijs $\mathbf{E}$, Kreimler S, McMinn A. The effect of community and family interventions on young people's physical activity levels: a review of reviews and updated systematic review. Br J Sports Med 2011:45:914-22.

130. Kriemler S, Meyer U, Martin E, et al. Effect of school-based interventions on physical activity and fitness in children and adolescents: a review of reviews and systematic update. Br J Sports Med 2011;45:924-31.

131. Bahr R, van Mechelen W, Kannus P. Prevention of sports injuries. In: Kjær M, Krogsgaard M, Magnusson P, et al. Textbook of Sports Medicine: Basic Science and Clinical Aspects of Sports Injury and Physical Activity. Oxford: Blackwell Science 2002:299-314

132. Ljungqvist A, Jenoure PJ, Engebretsen L, et al. The International Olympic Committee (IOC) consensus statement on periodic health evaluation of elite athletes, March 2009. Clin J Sport Med 2009;19:347-65.

133. Mountjoy M, Armstrong N, Bizzini L, et al. IOC consensus statement: 'training the elite child athlete'. Br J Sports Med 2008;42:163-4.

134. Engebretsen L, Steffen K, Bahr R, et al. The International Olympic Committee Consensus statement on age determination in high-level young athletes. Br J Sports Med 2010;44:476-84.

135. Fuller CW, Junge A, DeCelles J, et al. 'Football for Health'-a football-based health-promotion programme for children in South Africa: a parallel cohort study. Br J Sports Med 2010;44:546-54.

136. Faude 0, Kerper 0, Multhaupt M, et al. Football to tackle overweight in children. Scand J Med Sci Sports 2010;20(Suppl 1):103-10.

137. Dupre J. 'Capturing the Olympic Legacy in Your Classroom' Canadian Olympic School Program 2010-2011 Curriculum.

138. World Health Organization. Resolution WHA57.17. Global Strategy on Diet, Physical Activity and Health. Fifty-seventh World Health Assembly, Geneva, 17-22 May 2004. Resolutions and Decisions, Annexes. Geneva: World Health Organization, 2004

139. World Health Organization. 2008-2013 Action Plan for the Global Strategy for the Prevention and Control of Noncommunicable Diseases. Geneva: World Health Organization, 2008

140. World Health Organization. Global Recommendations on Physical Activity for Health. Geneva: World Health Organization, 2010.

141. Agita Mundo Network. São Caetano do Sul, Brazil. http://www.agitamundo.org/ site en.htm (accessed Jan 2011).

142. GAPA. Global Advocacy for Physical Activity, Advocacy Council of ISPAH. http:// www.globalpa.org.uk (accessed Jan 2011). 
143. Red de actividad fisica de las Americas. Physical Activity Network of the Americas RAFA-PANA. http://www.rafapana.org/index.php?lang=en (accessed Jan 2011).

144. World Health Organization. HEPA Europe (European Network for the Promotion of Health-enhancing Physical Activity). Copenhagen: WHO Regional Office for Europe. http://www.euro.who.int/hepa (accessed Jan 2011).

145. Asia Pacific Physical Activity Network. Sydney, Australia: Centre for Physical Activity and Health (CPAH), University of Sydney. http://www.ap-pan.org (accessed Jan 2011).

146. AFPAN African Physical Activity Network. http://www.essm.uct.ac.za/afpan (accessed Jan 2011).

147. Kelly P, Cavill N, Foster C. An Analysis of National Approaches to Promoting Physical Activity and Sports in Children and Adolescents. British Heart Foundation Health Promotion Research Group, University of Oxford for HEPA Europe. Copenhagen: WHO Regional Office for Europe, 2010.

148. Literature Reviews on Sport for Development and Peace. University of Toronto, Faculty of Physical Education and Health, commissioned by Sport for Development and Peace International Working Group (SDP IWG) Secretariat Toronto, Canada, 18 October 2007. http://www.righttoplay.com/International/news-and-media/Documents/Policy\%20 Reports\%20docs/Literature\%20Reviews\%20SDP.pdf (accessed 21 Mar 2011).

149. Sport and Health: Preventing Disease and Promoting Health. http://www. righttoplay.com/International/news-and-media/Documents/Policy\%20Reports\%20 docs/Harnessing\%20the\%20Power\%20-\%20FULL/Chapter2_SportandHealth.pdf (accessed 21 Mar 2011).

150. UNESCO. International Charter of Physical Education and Sport, Adopted by the General Conference on 21 November 1978, online UNESCO. http://www.unesco. org/education/

151. United Nations. International Covenant on Economic, Social and Cultural Rights (16 December 1966) A/ResS/2200 (A) XXI, entered into force 3 January 1976, at Article 12 (1).

152. World Bank. Operational Directive 14.70, NGO Research Guide, Duke University Libraries. http://library.duke.edu/research/subject/guides/ngo_guide/igo_ngo_coop/ ngo wb.html (accessed 21 Mar 2011).

153. Right to Play. Results - Our Report on Progress: 10 Years of Play 2000-2010. http://www.righttoplay.com/International/news-and-media/Documents/ Results_2010.pdf (accessed 21 Mar 2011).

154. Levermore R. Sport in international development: time to treat it seriously? Brown J World Aff 2008;14:55-66.

155. Matsudo VK, Matsudo SM, Araújo TL, et al. Time trends in physical activity in the state of São Paulo, Brazil: 2002-2008. Med Sci Sports Exerc 2010;42:2231-6.
156. van Sluijs EM, McMinn AM, Griffin SJ. Effectiveness of interventions to promote physical activity in children and adolescents: systematic review of controlled trials. BMJ 2007;335:703.

157. Naylor PJ, McKay HA. Prevention in the first place: schools a setting for action on physical inactivity. Br J Sports Med 2009;43:10-13.

158. Kriemler S, Zahner L, Schindler C, et al. Effect of school based physical activity programme (KISS) on fitness and adiposity in primary schoolchildren: cluster randomised controlled trial. BMJ 2010;340:c785.

159. Gibson CA, Smith BK, Dubose KD, et al. Physical activity across the curriculum: year one process evaluation results. Int J Behav Nutr Phys Act 2008:5:36.

160. de Meij JS, Chinapaw MJ, van Stralen MM, et al. Effectiveness of JUMP-in, a Dutch primary school-based community intervention aimed at the promotion of physical activity. Br J Sports Med 2010;Published Online First: 25 November 2010 doi:10.1136/bjsm.2010.075531.

161. Inman DD, van Bakergem KM, Larosa AC, et al. Evidence-based health promotion programs for schools and communities. Am J Prev Med 2011;40:207-19.

162. Stokols D. Establishing and maintaining healthy environments. Toward a social ecology of health promotion. Am Psychol 1992;47:6-22.

163. Durlak JA, DuPre EP. Implementation matters: a review of research on the influence of implementation on program outcomes and the factors affecting implementation. Am J Community Psychol 2008;41:327-50.

164. Swedish Council on Technology Assessment in Health Care (SBU). Methods of Promoting Physical Activity - A Systematic Literature Survey (English Summary). Swedish Council on Technology Assessment in Health Care Stockholm, 2007. http://www.sbu.se/upload/Publikationer/Content1/1/Fysisk sam ENG.pdf (accessed 23 Jun 2011).

165. Börjesson M, Hellénius ML, Jansson E, et al.; Professional Associations for Physical Activity (YFA, Sweden). Physical Activity in the Prevention and Treatment of Disease. Östersund: Swedish National Institute of Public Health 2010:1-633. http://www.fyss.se.

166. Hellénius ML, Sundberg CJ. Physical activity as medicine: time to translate evidence into clinical practice. Br J Sports Med 2011:45:158.

167. Kahle EB, Zipf WB, Lamb DR, et al. Association between mild, routine exercise and improved insulin dynamics and glucose control in obese adolescents. Int J Sports Med 1996;17:1-6.

168. Williams CL, Hayman LL, Daniels SR, et al. Cardiovascular health in childhood: a statement for health professionals from the Committee on Atherosclerosis, Hypertension, and Obesity in the Young (AHOY) of the Council on Cardiovascular Disease in the Young, American Heart Association. Circulation 2002;106:143-60. 


\section{Corrections}

Mountjoy M, Andersen LB, Armstrong N, et al. International Olympic Committee consensus statement on the health and fitness of young people through physical activity and sport (Br J Sports Med 2011;45:839-48). Author Andrew Hills' correct name is Andrew P Hills.

Br J Sports Med 2011;45:1063. doi:10.1136/bjsports-2011-090228corr1 